\title{
Histologic evaluation of femoral nerve demyelinating and axonal neuropathy in Wistar rats due to alendronate intake: a randomised study
}

Papamitsou Theodora, Papakoulas Apostolos, Papaliagkas Vasileios, Karachrysafi Sofia ${ }^{*}$ (i), Dietrich Eva-Maria and Sioga Antonia

\begin{abstract}
Background: Bisphosphonates (BPs) are forceful inhibitors of osteoclast-mediated bone resorption. Long-term $\mathrm{BP}$ use is associated with multiple rare but severe adverse effects. The objective of this study was to investigate the possible effects of BPs in the structure of femoral nerve. Specimens from the femoral nerve of ten female 12-month old Wistar rats were used as control group and ten female 12-month old Wistar rats to which Alendronate (Fosamax, Merck) was administered per os for 13 weeks, were used as research group. Samples were observed under a Transmission Electron Microscope. G ratio measurements and statistical analysis with SPSS program were also performed.

Results: The control group showed no major changes of the nerve's histologic image, with the exception of some spots of thickness of the nerve myelin sheath. The research group showed major morphological changes which varied from partial disorganization or thickening of the myelin to severe myelin thickening and axon strangulation. A statistically significant difference of the $\mathrm{G}$ ratio between the two groups was observed.

Conclusions: The reported values (found in literature) for the morphologic measurements of the femoral nerve in Wistar rats are not complying with the ones we found in our study. There was a significant reduction of all three variables (the mean axon like diameter, the myelin thickness, $\mathrm{G}$ ratio) studied in the femoral nerve of the research group in contrast to control group. Our study demonstrates a possible correlation between alendronate administration and femoral nerve's function, nevertheless due to the small specimen further research is needed.
\end{abstract}

Keywords: Bisphosphonates, Alendronate, Femoral nerve, G-Ratio

\section{Background}

Bisphosphonates (BPs) are forceful inhibitors of osteoclast-mediated bone resorption. During the last decades, their role as experimental agents was upgraded to becoming the treatment of choice for a variety of bone disorders, mostly osteoporosis, Paget's disease and hypercalcaemia of malignancy [1]. Their high affinity for

*Correspondence: sofia_karachrysafi@outlook.com Laboratory of Histology and Embryology, Faculty of Medicine, Aristotle University of Thessaloniki, 54124 Thessaloniki, Greece bone mineral, but not other tissues, indicates them as the ideal candidates for treatment of bone diseases [2].

Bisphosphonates are chemically stable derivatives of inorganic pyrophosphate (PPi), a naturally occurring compound in which two phosphate groups are linked by esterification [2]. In BPs, the oxygen bridge has been replaced by a carbon with various side chains $(\mathrm{P}-\mathrm{C}-\mathrm{P})$ [3]. It is clear that suppressing osteoclast bone resorption is their principal biologic effect, with the potency of this effect dependent on the side chains [1]. They bind to hydroxyapatite crystals, preferentially

c) The Author(s) 2020. This article is licensed under a Creative Commons Attribution 4.0 International License, which permits use, sharing, adaptation, distribution and reproduction in any medium or format, as long as you give appropriate credit to the original author(s) and the source, provide a link to the Creative Commons licence, and indicate if changes were made. The images or other third party material in this article are included in the article's Creative Commons licence, unless indicated otherwise in a credit line to the material. If material is not included in the article's Creative Commons licence and your intended use is not permitted by statutory regulation or exceeds the permitted use, you will need to obtain permission directly from the copyright holder. To view a copy of this licence, visit http://creativeco mmons.org/licenses/by/4.0/. The Creative Commons Public Domain Dedication waiver (http://creativecommons.org/publicdomain/ zero/1.0/) applies to the data made available in this article, unless otherwise stated in a credit line to the data. 
incorporating into sites of active bone remodeling and reduce bone turnover by inducing osteoclast apoptosis. The first generation of non-nitrogen-containing BPs (etidronate, clodronate, and tiludronate) inhibit osteoclasts by inhibiting the ATP-dependent cellular processes, while the nitrogen-containing BPs (alendronate, risedronate, ibandronate, pamidronate, and zoledronic acid) inhibit the farnesyl pyrophosphate (FPP) synthase and lead to the same outcome [2].

Pharmacokinetically, they are very hydrophilic and poorly absorbed by the gastrointestinal tract due to their poor lipophilicity. Systemically available BPs disappear very rapidly from plasma and about $50 \%$ of the absorbed drug is taken up selectively by the skeleton. The rest is excreted in urine without being metabolised, as renal excretion is the only route of elimination [4]. The skeleton has a very high capacity to retain BPs, which, after bone uptake, are slowly released into the circulation and eliminated from the kidneys. The relative contribution of these two procedures to the overall obliteration from plasma differs significantly among BPs [5].

Nevertheless, long-term BP use is associated with multiple rare but severe adverse effects. More specifically, adverse effects include events of the gastrointestinal tract, such as abdominal pain, nausea, dyspepsia, vomiting and diarrhea [6], osteonecrosis of the jaw [7] and the maxillae [8], osteonecrosis of the external ear canal [9], hypocalcaemia [10,11], atypical femoral fractures [12] or subtrochanteric fractures [13], carpal tunnel syndrome [14], renal failure [15], oesophageal cancer [16], uveitis with macular edema [17], interface dermatitis [18], orbital inflammation [19] and non-contact allergenic drug-induced baboon syndrome [20]. Recently, according to Cibickova et al. [21] experimental evidence has been provided that supports the idea of alendronate inhibiting cholesterol biosynthesis on the central nervous system. Therefore, awareness is being raised at the effects of BPs on the peripheral nervous system as well.

Reviewing of scientific bibliography revealed that there are not many research efforts regarding the influences of BP use either on the central or on the peripheral nervous system. In our report, we have studied the effects of BP use on the femoral nerve.

\section{Methods}

\section{Ethical approval}

This study was approved by the Bioethics Committee of the Medical School of the Aristotle University of Thessaloniki.

\section{Study design}

Twenty female Wistar rats, 12-month old, weighing approximately $500 \mathrm{~g}$, were used in the experiment. Rats were housed in stainless steel cages, with one rat per cage, $12 \mathrm{~h}$ light-dark cycle and relative humidity (35\%) and temperature control $\left(23 \pm 2{ }^{\circ} \mathrm{C}\right)$.

The animals were randomly allocated into two groups: Group A, the research group, that consisted of 10 animals, and Group B, the control group, that also consisted of 10 animals. Alendronate (Fosamax, Merck) was administered per os to animals of Group A at a dose of $0.05 \mathrm{mg} \mathrm{kg}^{-1}$ body weight per week dissolved in $3 \mathrm{cc}$ normal saline for a period of 13 weeks. The drug was administered thirty minutes prior to breakfast. The dose was calculated according to the usual human dose [22, 23]. The duration of the study was limited to 13 weeks and after euthanasia, the femoral nerve of the animals was removed and specimens were processed for electron microscopy examination. In this research we sampled three areas from each femoral nerve fiber (a total of 30 areas from each group), with every nerve part given the equal chance of being sampled.

\section{Transmission electron microscopy}

Femoral nerve tissue samples were sectioned into $<1 \mathrm{~cm}^{3}$ pieces. They were placed into glutaraldehyde $3 \%$ for $2 \mathrm{~h}$, followed by $1 \mathrm{~h}$ into osmium tetroxide $\left(\mathrm{OsO}_{4}\right) 1 \%$. Staining was performed with uranyl acetate $1 \%$ for $16 \mathrm{~h}$ and then samples were dehydrated with increased ethanol concentrations. Samples were embedded into Epon resin and ultra-thin sections $(60-90 \mathrm{~nm})$ were taken. Finally, sections were stained with Reynolds's stain. Samples were observed under a TEM JEOL 1011 in $80 \mathrm{kV}$ (Japan).

\section{$G$ ratio measurements}

Images were processed with National Institutes of Health ImageJ software [24] for quantification. The $G$ ratios of myelinated fibers were calculated as the ratio of the axonal diameter to the diameter of the myelinated fiber as measured using Image J software (G ratio calculator plugin). Moreover myelin thickness was examined in four different locations and mean $\pm S D$ value was assessed [24].

\section{Statistical analysis}

The results of study were analysed using IBM SPSS Statistics ver. 24. Continuous data were expressed as the mean difference (MD) and Standard Deviation (SD). The Kolmogorov-Smirnov test was used to determine whether our data were skewed or not. Furthermore $t$ test for independent variables and both $p$ ratio and confidence of interval $(\mathrm{CI})$ were used to compare the data extracted. 


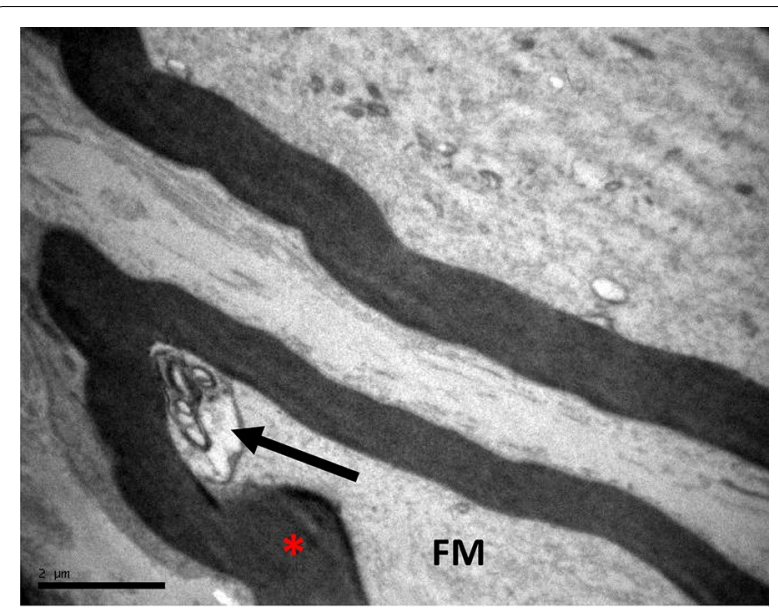

Fig. 1 Control group: Femoral nerve (FM) with no major changes with the exception of some spots of thickness of the nerve myelin sheath (red asterisk) and small detachment of the axon (arrow)

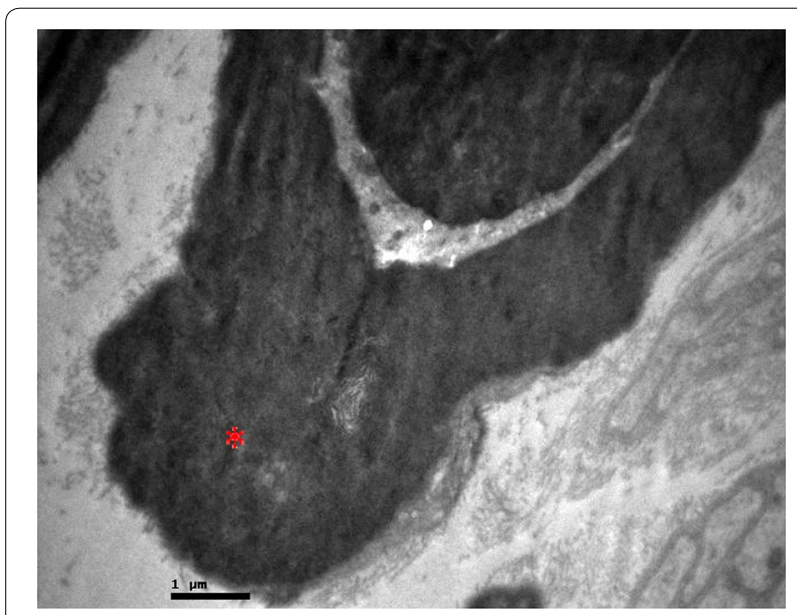

Fig. 2 Research group: myelin thickening (red asterisk)

$p$-values of 0.05 and CI of $95 \%$ were used as thresholds for statistical significance.

\section{Results}

\section{Morphological comparison}

In control group, most of the nerves were physiological and few of them showed detachment of the axon and small local thickening of myelin sheath (Fig. 1).

In research group, in all samples the degenerative changes were more profound. These changes were the detachment of the axon, the thickening of the myelin sheath that varied from light to severe which lead in axon strangulation (Figs. 2 and 3) as well as the vacuolization and disorganization of the myelin sheath (Fig. 4).

\section{Statistical analysis}

On top of these morphological changes a difference between the axon diameter of control and research group, myelin thickness and $G$ ratio were found. The $G$ ratio is defined as the ratio of the inner axonal diameter to the total outer diameter and has been utilised by several researchers. The $\mathrm{G}$ ratio may indicate abnormal reciprocal signaling between the axon and the myelinating Schwann cell, or may highlight thin myelin or conversely thin axons.

These measurements were recorded in different neuron sites of both groups. The minimum, maximum, mean value and standard deviation were recorded. As seen in Table 1 there is a difference between research and control group. Furthermore, there was a statistically significant difference of the $\mathrm{G}$ ratio between the two groups $[p<0.05$ and CI (95\%): $(-0.19,-0.011)]$ (Table 2). In Table 3, the results of the independent samples $t$ test are presented.

\section{Discussion}

Rushton was the first researcher who evaluated the G ratio in Central Nervous System (CNS) and peripheral nerves. Since Rushton derived an optimal theoretical G ratio of 0.6 [25], many studies attempted to address the matter. According to Chomiak and $\mathrm{Hu}$, a theoretically optimized G ratio both for central nervous fibers (0.77) and for peripheral nervous fibers (0.6) can be calculated [26]. Although the theoretical measurements produced by Chomiak and $\mathrm{Hu}$ algorithm fall into small range with the ones expected by the observed $\mathrm{G}$ ratio in the literature ( $\mathrm{G}$ ratio observed $=0.76-0.81$ ) in the CNS, there is a noticeable difference between his measurements and the $\mathrm{G}$ ratio in peripheral nerves.

More specifically, Bega et al. [27] used Wistar rats to study the $G$ ratio of the femoral nerve and whether age and training can be related to changes in the nerve fibers. According to their analysis of structural changes of the femoral nerve, the mean axon diameter was $4.2 \pm 0.2 \mu \mathrm{m}$ in sedentary and $5.6 \pm 0.3 \mu \mathrm{m}$ in trained rats, the mean myelin sheath thickness was $2.4 \pm 0.3 \mu \mathrm{m}$ in sedentary and $1.8 \pm 0.28 \mu \mathrm{m}$ in trained rats and the mean G ratio $0.60 \pm 0.12$ in sedentary and $0.64 \pm 0.11$ in trained rats [27].

The values reported in literature for the morphologic measurements of the femoral nerve in Wistar rats are not complying with the ones we found in our study. The mean Axon like Diameter in our control group of Wistar rats was $17.8 \pm 4.39 \mu \mathrm{m}$, the myelin thickness $4.09 \pm 0.79 \mu \mathrm{m}$ and $\mathrm{G}$ ratio $0.71 \pm 0.86$. On the other hand, there was a significant reduction of all three variables studied in the femoral nerve of the research group. Considering that $\mathrm{G}$ ratio is reliable for assessing 


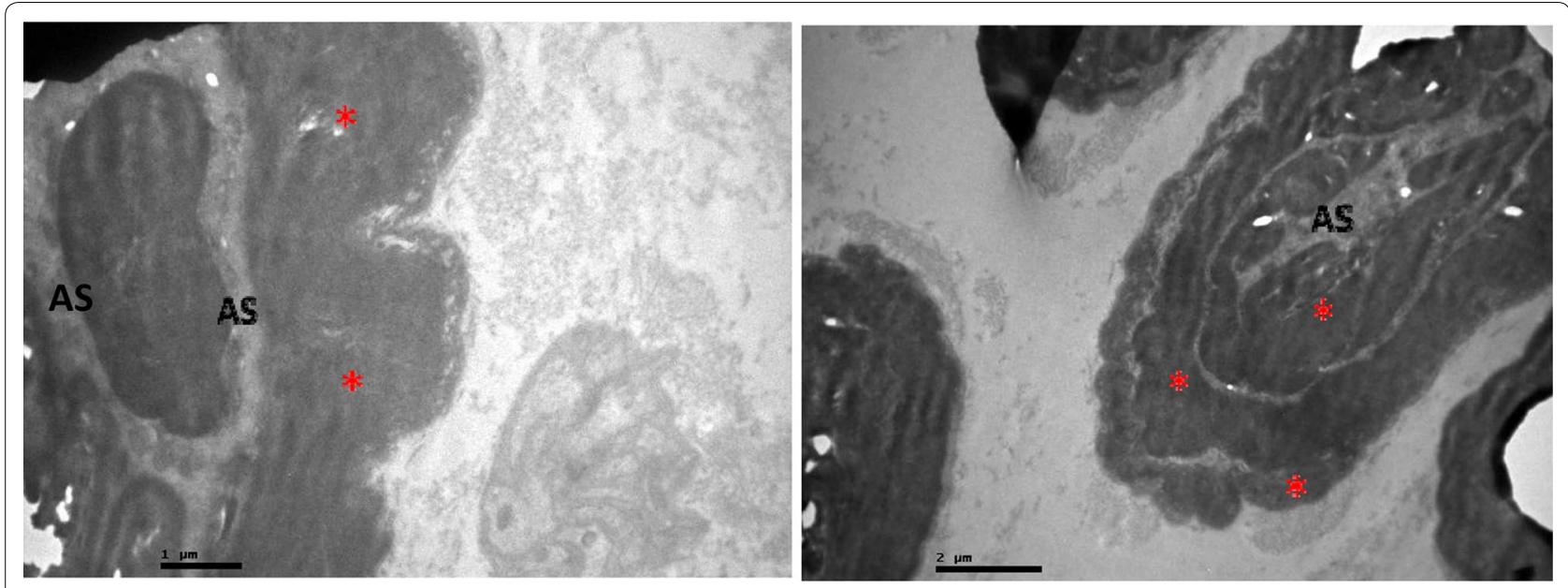

Fig. 3 Effects of alendronate on femoral nerve of research group. Myelin thickening (red asterisk) and axon strangulation (AS)
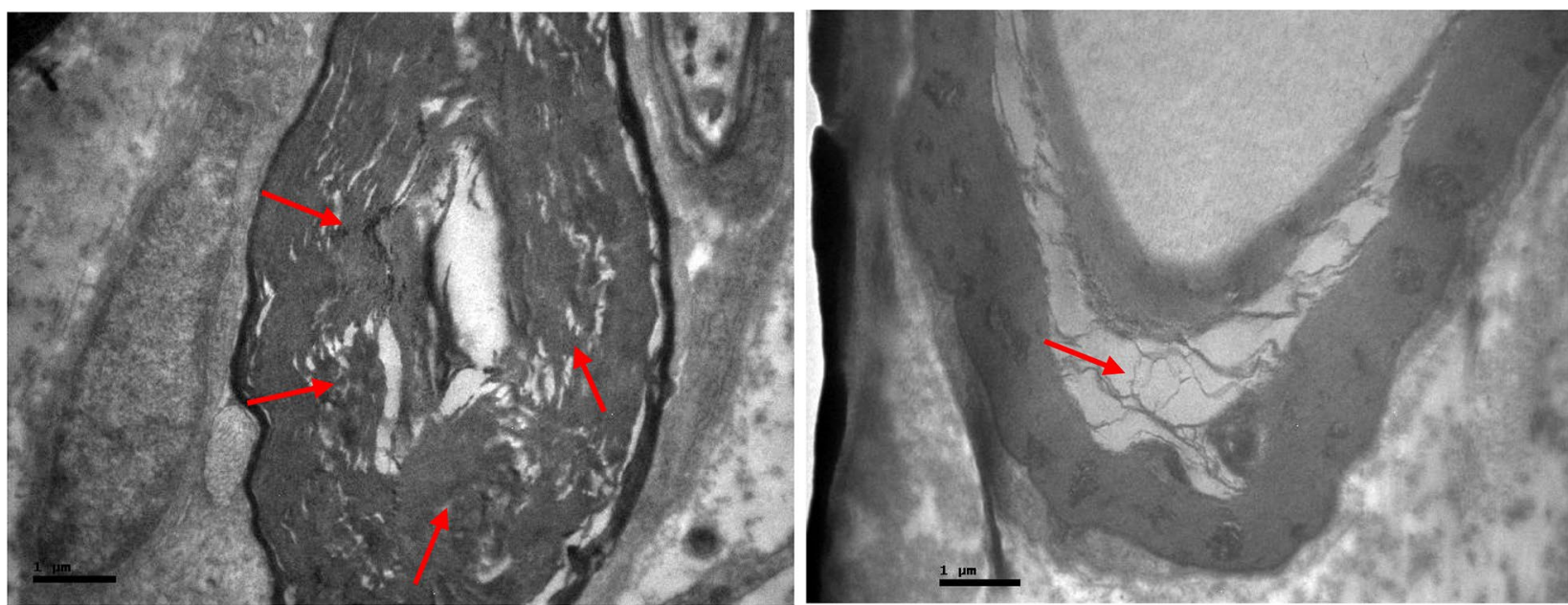

Fig. 4 Effects of alendronate on femoral nerve of research group. Myelin partial disorganisation and vacuolization (red arrow)

Table 1 Morphological parameters of femoral nerve in research and control groups

\begin{tabular}{lcc}
\hline & Research group & Control group \\
\hline Axon like diameter & $6.04 \pm 1.50$ & $17.80 \pm 4.39$ \\
Myelin thickness & $1.78 \pm 0.48$ & $4.09 \pm 0.79$ \\
\hline
\end{tabular}

Table 2 Mean value of G ratio for femoral nerve

\begin{tabular}{lll}
\hline & Research group & Control group \\
\hline G ratio & 0.60 (std. error mean 0.03) & $0.71($ std. error mean 0.02) \\
\hline
\end{tabular}

Table 3 Difference in $\mathrm{G}$ ratio for femoral nerve in rats of control and research groups

\begin{tabular}{|c|c|c|c|c|}
\hline & \multicolumn{2}{|l|}{ t Test } & \multicolumn{2}{|c|}{$\begin{array}{l}95 \% \mathrm{Cl} \\
\text { of the difference }\end{array}$} \\
\hline & $\begin{array}{l}\text { Mean } \\
\text { difference }\end{array}$ & $\begin{array}{l}\text { Std. error } \\
\text { difference }\end{array}$ & Lower & Upper \\
\hline \multicolumn{5}{|l|}{ G ratio } \\
\hline $\begin{array}{l}\text { Equal variances } \\
\text { assumed }\end{array}$ & -0.104 & 0.044 & -0.196 & -0.012 \\
\hline
\end{tabular}

axonal myelination and function of the femoral nerve, the use of alendronate in Wistar rats in dosage suggested for human patients can be considered a distinct 
factor affecting the normal function of femoral nerve fibers. On top of that, nerve conduction velocity (NVC), a reliable factor used for measuring the nerve's condition, is closely related to a decrease of axon diameter and myelin of the myelinated fibers [28]. Although we did not measure the NVC in our experiment, it would be a very interesting variable, for our colleagues to use in such studies in the future. In any case, more research is needed to determine how these changes will affect the nerve's function in long lasting treatment with BPs.

The difference between the measurements in our control group and the measurements we found in the bibliography could be due to the small sample we used. However, there are no large studies that have recorded these parameters of the femoral nerve in Wistar rats and that could be used as reference in our experimental study. To our knowledge no systematical bias could have caused this difference.

\section{Conclusions}

In conclusion, the literature values for the morphologic measurements of the femoral nerve in Wistar rats are not complying with the ones we found in our study. There was a significant reduction of all three variables (the mean axon like diameter, the myelin thickness, $G$ ratio) studied in the femoral nerve of the research group in contrast to control group. Our study demonstrates a possible correlation between alendronate administration and femoral nerve's function, nevertheless due to the small specimen further research is needed.

\section{Acknowledgements}

Not applicable.

\section{Authors' contributions}

PT performed the histological examination of the femoral nerve, and was a major contributor in writing the manuscript. SA performed the histological examination of the femoral nerve, and was a major contributor in writing the manuscript. PV analyzed and interpreted the data regarding axon diameter, myelin thickness and g-ratio of all samples, conducted the statistical analysis and was a major contributor in writing the manuscript. PA was a major contributor in writing the manuscript. KS was a major contributor in writing the manuscript. DEM performed the selection of the tissues, the preparation for histological examination and was a major contributor in writing the manuscript. All authors read and approved the final manuscript.

\section{Funding}

The research received no funding. It was supported by the Faculty of Medicine of Aristotle University of Thessaloniki.

\section{Availability of data and materials}

Please contact author for data requests.

\section{Ethics approval and consent to participate}

The protocol number of the research's statement on ethics approval and consent is 1.135/8-11-12 and was provided by the Committee for Bioethics and Ethics of Faculty of Medicine, Aristotle University of Thessaloniki.
Consent for publication

Not applicable.

\section{Competing interests}

The authors declare that they have no competing interests.

Received: 14 November 2019 Accepted: 6 February 2020

Published online: 18 February 2020

References

1. Reid IR. Bisphosphonates: new indications and methods of administration. Curr Opin Rheumatol. 2003;15:458-63.

2. Drake MT, Clarke BL, Khosla S. Bisphosphonates: mechanism of action and role in clinical practice. Mayo Clin Proc. 2008;83:1032-45.

3. Rodan GA, Fleisch HA. Biphosphonates: mechanisms of action. J Clin Invest. 1996;97:2692-6.

4. Cremers SC, Pillai G, Papapoulos SE. Pharmacokinetics/pharmacodynamics of bisphosphonates: use for optimisation of intermittent therapy for osteoporosis. Clin Pharmacokinet. 2005;44:551-70.

5. Lin JH. Bisphosphonates: a review of their pharmacokinetic properties. Bone. 1996;18:75-85.

6. Vogtmann E, Corley DA, Almers LM, Cardwell CR, Murray LJ, Abnet CC. Oral bisphosphonate exposure and the risk of upper gastrointestinal cancers. PLOS ONE. 2015;10:e0140180.

7. Soós B, Vajta L, Szalma J. Sunitinib and zoledronic acid induced osteonecrosis of the jaw. Orv Hetil. 2015;156:1865-70.

8. da Silva Santos PS, Oliveira MA, Felix VB. Bisphosphonate-induced maxillofacial osteonecrosis in osteoporotic individuals. Rev Bras Ortop. 2011;46:495-9.

9. Bast F, Fuss H, Schrom T. Bilateral bisphosphonate-associated osteonecrosis of the external ear canal: a rare case. HNO. 2012;60:1127-9.

10. Hanamura M, Iwamoto T, Soga N, Sugimura Y, Okuda M. Risk factors contributing to the development of hypocalcemia after zoledronic acid administration in patients with bone metastases of solid tumor. Biol Pharm Bull. 2010;33:721-4.

11. Kreutle V, Blum C, Meier C, Past M, Müller B, Schütz P, Borm K. Bisphosphonate induced hypocalcaemia-report of six cases and review of the literature. Swiss Med Wkly. 2014;144:W13979.

12. Găleşanu C, Mocanu V, Buzdugă C, Florescu A, Zaharia V, Lisnic V. Atypical femoral fractures after long-term bisphosphonates therapy: case report. Rev Med Chir Soc Med Nat lasi. 2016;120:114-8.

13. Rizzoli R, Akesson K, Bouxsein M, Kanis JA, Napoli N, Papapoulos S, Reginster JY, Cooper C. Subtrochanteric fractures after long-term treatment with bisphosphonates: a European society on clinical and economic aspects of osteoporosis and osteoarthritis, and international osteoporosis foundation working group report. Osteoporos Int. 2011;22:373-90.

14. Carvajal A, Martín Arias LH, Sáinz M, Escudero A, Fierro I, Sauzet O, et al. Carpal tunnel syndrome associated with oral bisphosphonates. A population-based cohort study. PLoS ONE. 2016;11:e0146772.

15. Gartrell BA, Coleman RE, Fizazi K, Miller K, Saad F, Sternberg CN, et al. Toxicities following treatment with bisphosphonates and receptor activator of nuclear factor-kB ligand inhibitors in patients with advanced prostate cancer. Eur Urol. 2014;65:278-86.

16. Green J, Czanner G, Reeves G, Watson J, Wise L, Beral V. Oral bisphosphonates and risk of cancer of oesophagus, stomach, and colorectum: casecontrol analysis within a UK primary care cohort. BMJ. 2010;341:c4444.

17. Tian Y, Wang R, Liu L, Ma C, Lu Q, Yin F. Acute bilateral uveitis and right macular edema induced by a single infusion of zoledronic acid for the treatment of postmenopausal osteoporosis as a substitution for oral alendronate: a case report. BMC Musculoskelet Disord. 2016;17:72.

18. Succaria F, Collier M, Mahalingam M. Zoledronic acid-induced interface dermatitis. Am J Dermatopathol. 2015;37:933-5.

19. Pirbhai A, Rajak SN, Goold LA, Cunneen TS, Wilcsek G, Martin P, et al. Bisphosphonate-induced orbital inflammation: a case series and review. Orbit. 2015;34:331-5.

20. Cohen PR. Zoledronic acid-associated symmetrical drug-related intertriginous and flexural exanthema (SDRIFE): report of baboon syndrome in a woman with recurrent metastatic breast cancer after receiving zoledronic acid. Dermatol Online J. 2015;21:2. 
21. Cibičková L, Hyšpler R, Cibiček N, Čermáková E, Palička V. Alendronate lowers cholesterol synthesis in the central nervous system of rats-a preliminary study. Physiol Res. 2009;58:455-8.

22. Dhillon S, Lyseng-Williamson KA. Zoledronic acid: a review of its use in the management of bone metastases of malignancy. Drugs. 2008;68:507-34.

23. Pozzi S, Marcheselli R, Falorio S, Masini L, Stelitano C, Falcone A, et al. Bisphosphonates-associated osteonecrosis of the jaw: a long-term follow-up of a series of 35 cases observed by GISL and evaluation of its frequency over time. Am J Hematol. 2009;84:850-2.

24. Rueden CT, Schindelin J, Hiner MC, DeZonia BE, Walter AE, Arena ET. Image J2: imagej for the next generation of scientific image data. BMC Bioinform. 2017;18:529.

25. Rushton WAH. A theory of the effects of fibre size in medullated nerve. $J$ Physiol. 1951;115:101-22.
26. Chomiak T, Hu B. What is the optimal value of the g-ratio for myelinated fibers in the rat CNS? A theoretical approach. PLoS ONE. 2009;4:e7754

27. Bega A, Bocalini DS, Garoto RC, de Lima Maciel CC, da Silva AA, de Andrade NS, et al. Positive changes in femoral nerve morphometry in older rats following aerobic training. Exp Gerontol. 2018;110:92-7.

28. Vardú E, Ceballos D, Vilches JJ, Navarro X. Influence of ageing on peripheral nerve function and regeneration. J Peripher Nerv Syst. 2000;5:191-208.

\section{Publisher's Note}

Springer Nature remains neutral with regard to jurisdictional claims in published maps and institutional affiliations.
Ready to submit your research? Choose BMC and benefit from:

- fast, convenient online submission

- thorough peer review by experienced researchers in your field

- rapid publication on acceptance

- support for research data, including large and complex data types

- gold Open Access which fosters wider collaboration and increased citations

- maximum visibility for your research: over $100 \mathrm{M}$ website views per year

At BMC, research is always in progress.

Learn more biomedcentral.com/submissions 